\title{
Autoinducer production and quorum-sensing dependent phenotypes of Pseudomonas aeruginosa vary according to isolation site during colonization of intubated patients Sabine Favre-Bonté ${ }^{1,4}$, Eric Chamot ${ }^{2}$, Thilo Köhler ${ }^{1}$, Jacques-A Romand ${ }^{3}$ and Christian van Delden*1
}

Address: ${ }^{1}$ Service des Maladies Infectieuses, Hôpital Universitaire de Genève, Rue Micheli-du- Crest 24, CH-1211 Genève 14, Switzerland, ${ }^{2}$ Department of Epidemiology, University of Alabama, Birmingham, USA, ${ }^{3}$ Service des Soins Intensifs, Hôpital Universitaire de Genève, Genève, Switzerland and ${ }^{4}$ UMR CNRS 5557-Ecologie Microbienne, Université Claude Bernard, Lyon 1, France

Email: Sabine Favre-Bonté - favre@biomserv.univ-lyon1.fr; Eric Chamot - echamot@uab.edu; Thilo Köhler - Thilo.Kohler@medecine.unige.ch; Jacques-A Romand - Jacques-Andre.Romand@hcuge.ch; Christian van Delden* - christian.vandelden@medecine.unige.ch

* Corresponding author

Published: 18 April 2007

BMC Microbiology 2007, 7:33 doi:10.1 186/147|-2180-7-33
Received: 16 September 2006

Accepted: 18 April 2007

This article is available from: http://www.biomedcentral.com/I47I-2/80/7/33

(c) 2007 Favre-Bonté et al; licensee BioMed Central Ltd.

This is an Open Access article distributed under the terms of the Creative Commons Attribution License (http://creativecommons.org/licenses/by/2.0), which permits unrestricted use, distribution, and reproduction in any medium, provided the original work is properly cited.

\begin{abstract}
Background: Pseudomonas aeruginosa frequently colonizes and is responsible for severe ventilatorassociated pneumonia in intubated patients. A quorum-sensing (QS) circuit, depending on the production of the two QS-signaling molecules (autoinducers, Als) 3-oxo- $\mathrm{C}_{12}-\mathrm{HSL}$ and $\mathrm{C}_{4}-\mathrm{HSL}$, regulates the production by $P$. aeruginosa of several virulence factors and is required for biofilm formation. Therefore QS-inhibition has been suggested as a new target for preventive and/or therapeutic strategies. However the precise role of QS during colonization and subsequent infections of intubated patients remains unclear.

Results: We wondered whether QS is active during colonization of intubated patients, and whether $P$. aeruginosa isolates growing inside the biofilm covering the intubation devices and those resident in the lungs of colonized patients differ in their QS-dependent phenotypes. We collected the intubation devices of eight patients colonized by $P$. aeruginosa. We detected 3-oxo- $\mathrm{C}_{12}-\mathrm{HSL}$ on eight, and $\mathrm{C}_{4}-\mathrm{HSL}$ on six of these devices. In three of these patients we also obtained $P$. aeruginosa isolates from tracheal aspirates at the time of extubation $(n=18)$, as well as isolates from the intubation devices $(n=25)$. We genotyped these isolates, quantified their Als production, and determined three QS-dependent phenotypes (adherence capacity, biofilm and elastase production). The production of 3-oxo- $\mathrm{C}_{12}-\mathrm{HSL}$ was consistently increased for isolates from the intubation devices, whereas the production of $\mathrm{C}_{4}-\mathrm{HSL}$ was significantly higher for isolates from tracheal aspirates. Isolates from tracheal aspirates produced significantly higher amounts of elastase but less biofilm, and had a marginally reduced adhesion capacity than isolates from the intubation devices. Levels of 3-oxo- $\mathrm{C}_{12}-\mathrm{HSL}$ and elastase production correlated statistically for tracheal intubation isolates, whereas levels of $3-0 \times 0-C_{12}-H S L$ production and adhesion ability, as well as biofilm production, correlated weakly amongst intubation device isolates.
\end{abstract}

Conclusion: Our findings demonstrate that autoinducers are produced during the colonization of intubated patients by $P$. aeruginosa. The microenvironment, in which $P$. aeruginosa grows, may select for bacteria with different capacities to produce autoinducers and certain QS-dependent phenotypes. QSinhibition might therefore affect differently isolates growing inside the biofilm covering intubation devices and those resident in the lungs. 


\section{Background}

Pseudomonas aeruginosa is an opportunistic pathogen implicated in a wide variety of infections, particularly in burn victims, cancer patients and cystic fibrosis (CF) patients. In addition $P$. aeruginosa is a major cause of severe pneumonia in mechanically ventilated patients [1]. Such ventilator-associated pneumonia (VAP) are almost always preceded by the colonization of the upper respiratory tract. The presence of the intubation device is a major risk factor for this colonization [2]. As such the capacities of $P$. aeruginosa to adhere to the inert surface and grow inside a biofilm on the intubation device are thought to be essential for the subsequent colonization and infection of the lower respiratory tract [3].

After colonizing the respiratory tract of intubated patients, $P$. aeruginosa causes infections and extensive damage to host tissues via the production of a number of extracellular virulence factors [4]. The expression of several of these factors is controlled by a quorum-sensing (QS) circuitry involving at least two autoinducers (AIs): N-(3-oxododecanoyl)-Homoserine Lactone (3-oxo- $\left.\mathrm{C}_{12}-\mathrm{HSL}\right)$ and $\mathrm{N}$ butyryl-L-Homoserine Lactone $\left(\mathrm{C}_{4}\right.$-HSL) [4]. The production of 3-oxo- $\mathrm{C}_{12}$-HSL and $\mathrm{C}_{4}$-HSL requires the autoinducer synthases encoded by the lasI and rhlI genes, respectively. These QS-systems were first described for their role in the regulation of extracellular virulence factors $[5,6]$ but have recently been shown to regulate many other bacterial functions including biofilm formation [7$10]$.

The importance of a functional QS-circuit for the virulence of $P$. aeruginosa has been clearly established in vivo in animal models [11]. As a consequence QS-inhibition has been suggested as a potential target for new preventive and/or therapeutic strategies of $P$. aeruginosa infections.

However the precise role during human infections remains speculative. Most studies so far have focused on the capacity of clinical isolates to produce the two autoinducers and on the detection of the two AIs directly in clinical samples. $P$. aeruginosa isolates from CF patients produce AIs in vitro [12], and sputum of CF patients colonized by $P$. aeruginosa produces the same signals ex vivo [13]. AIs have also been detected in situ in CF lung tissue $[14]$, in the sputum of CF patients $[15,16]$, and in bronchoalveolar lavage fluid after lung transplantation [17]. Recently we observed that most strains initially colonizing intubated patients are QS-proficient [18]. Both 3-oxo- $\mathrm{C}_{12^{-}}$ HSL and $\mathrm{C}_{4}$-HSL have also been detected in biofilms, both in vivo and in situ $[15,16,19]$; moreover their relative abundance has been suggested as a marker for the biofilm mode of growth in CF patients [13].
Because much remains to be understood about the role of QS during human infections, and the potential of QSinhibition in their prevention and/or treatment, we examined the behavior of QS during the colonization of intubated patients. To determine whether QS is active during the colonization of intubated patients, we first extracted and quantified AIs directly from the intubation devices of patients colonized with P.aeruginosa. Because of the multitude of phenotypes depending on QS we then wondered whether $P$. aeruginosa isolates growing in different microenvironments might vary in their capacity to produce AIs and differ in their expression of QS-dependent phenotypes. We therefore collected $P$. aeruginosa isolates from the surface of intubation devices and from tracheal aspirates obtained from the same patients on the day of extubation. For each patient, we grouped strains according to their genotype, and characterized them in terms of production of autoinducers, and capacity to adhere to PVC, and produce elastase and biofilm. Our results suggest that the relative production of autoinducers, and the QSdependent phenotypes of $P$. aeruginosa vary according to their site of isolation.

\section{Results \\ Study population}

Patients' clinical characteristics are presented in Table 1. Underlying diseases included polytrauma, intra-cerebral hemorrhage, congestive heart failure and non-pseudomonal sepsis. Duration of mechanical ventilation ranged from 9 to 24 days. Detailed clinical characteristics are provided for the three patients from whom $P$. aeruginosa isolates were collected both from the intubation device and from a tracheal aspirate on the day of extubation:

Patient 8 was a 27-year-old male who suffered a severe polytrauma including cerebral contusion and hemorrhage. $P$. aeruginosa was cultured for the first time from his tracheal aspirates 7 days after his intubation. Therapeutic retreat was decided after 15 days of mechanical ventilation and he died without having received any antibiotics. The presence of $P$. aeruginosa in his tracheal aspirates was considered as colonization. The tracheal aspirate used in the present study was collected shortly before his death and extubation.

Patient 12 was a 21-year-old female who suffered a severe polytrauma including a cranio-cerebral trauma with diffuse axonal lesions and multiple rib fractures. $P$. aeruginosa was first cultured in bronchoalveolar lavage fluid four days after her intubation. $P$. aeruginosa pneumonia was diagnosed two days later and she was treated with an imipenem - tobramycin combination therapy. The clinical response was satisfying and she was extubated 3 days later still on antimicrobial therapy. A tracheal aspirate was obtained on the day of extubation. 
Table I: Patient characteristics and intubation devices

\begin{tabular}{|c|c|c|c|c|c|}
\hline Patient & Underlying disease & $\begin{array}{c}\text { Duration of intubation } \\
\text { (days) }\end{array}$ & Tracheal aspirate on day of extubation & $\begin{array}{l}\text { 3-oxo- } \mathrm{C}_{12}-\mathrm{HSL} \\
\text { (nmoles/cuff) }\end{array}$ & $\begin{array}{c}\mathrm{C}_{4}-\mathrm{HSL} \\
\text { (nmoles/cuff) }\end{array}$ \\
\hline 2 & Polytrauma & 9 & no & 0.4 & 100 \\
\hline 5 & Nonpseudomonal sepsis & 13 & no & 0.5 & 17 \\
\hline 7 & Intra-cerebral hemorrhage & 24 & no & $>10$ & 22 \\
\hline 8 & Polytrauma & 15 & yes & $>10$ & 22 \\
\hline 11 & Polytrauma & 18 & no & $>10$ & 300 \\
\hline 12 & Polytrauma & 9 & yes & $>10$ & 2 \\
\hline 13 & Congestive heart failure & 17 & yes & $>10$ & 2 \\
\hline 14 & Polytrauma & 16 & no & 6 & 24 \\
\hline
\end{tabular}

Patient 13 suffered severe congestive heart failure with a cardiac arrest. $P$. aeruginosa was first cultured from a tracheal aspirate three days after her intubation. P. aeruginosa pneumonia was treated with cefepime during 10 days starting 6 days after intubation. She remained colonized by $P$. aeruginosa and was extubated after 17 days of mechanical ventilation.

\section{In situ quantification of autoinducers on intubation devices}

The cuff of each endotracheal intubation device was removed and autoinducers were extracted from the biofilm as described in Materials and Methods. 3-oxo- $\mathrm{C}_{12}-\mathrm{HSL}$ was detected on all cuffs, the amounts varying between 0.4 and more than 10 nmoles per cuff (Table 1 ). $\mathrm{C}_{4}$-HSL was detected on six of the eight devices tested and its amount varied between 17 and 300 nmoles per cuff (Table 1). The in situ isolation of autoinducers from biofilms of the majority of the intubation devices suggests that QS might play a role during colonization by $P$. aeruginosa of such devices. The fact that we detected $\mathrm{C}_{4}$-HSL only from 6 devices could result from the lower sensitivity of our $\mathrm{C}_{4}$-HSL bioassay ( 2 nmoles/cuff) compared to the one used to quantify 3-oxo- $\mathrm{C}_{12}$-HSL (0.01 nmoles/cuff).

\section{Collection of P. aeruginosa isolates colonizing the intubation devices and the lungs of intubated patients}

For the three patients in whom we obtained tracheal aspirates (TA) at the time of extubation we also collected $P$. aeruginosa isolates directly from the cuff of the intubation device (ID) as described in Material and Methods. The complete collection consisted of 18 TA isolates and 25 ID isolates partitioned as shown in Table 2. Genotyping of these strains by RAPD identified 4 different genotypes (B, C, D and P). Genotypes C ( 3 isolates from patient 12 and 1 isolate from patient 13) and P (3 isolates from patient 13) were only found in tracheal aspirates and were therefore excluded from the analyses described in the following paragraphs, when not otherwise stated. The final collection therefore consisted of 11 TA and 25 ID isolates representing genotype $\mathrm{B}$ (8 TA and 21 ID isolates) and genotype D (3 TA and 4 ID isolates) (Table 2).

\section{Phenotypic characterization of TA and ID P. aeruginosa isolates}

(i) In vitro autoinducer production

We extracted and quantified the two autoinducers from culture supernatants of TA and ID isolates. All isolates produced both autoinducers in vitro, though levels varied according to the site of isolation (Table 2). Figure $1 \mathrm{~A}$ and $1 \mathrm{~B}$ show the mean production of both AIs for the isolates obtained from TA and ID for each individual patient. For the three patients ID isolates consistently produced higher amounts of 3-oxo- $\mathrm{C}_{12}$-HSL than TA isolates (Fig. 1A). When all the ID isolates were compared to the TA isolates the mean production of 3-oxo- $\mathrm{C}_{12}$-HSL was increased in the ID group $\left(1.6 \times 10^{-6} \mathrm{M}\right.$; Standard Error [SE], $4.8 \times 10^{-}$ $\left.{ }^{7} \mathrm{M}\right)$, compared to the TA group $\left(4.0 \times 10^{-7} \mathrm{M} ; \mathrm{SE}, 7.4 \times 10^{-}\right.$ ${ }^{8} \mathrm{M}, \mathrm{p}=0.12$ ) without reaching statistical significance, possibly due to the small sample size. In contrast the TA isolates of all patients produced higher amounts of $\mathrm{C}_{4}{ }^{-}$ HSL than the ID isolates (Fig. $1 \mathrm{~B}$ ), and the mean $\mathrm{C}_{4}$-HSL concentration was significantly higher for the TA isolates group $\left(1.2 \times 10^{-5} \mathrm{M}\right.$; SE, $\left.1.7 \times 10^{-6} \mathrm{M}\right)$ than for the ID isolates group $\left(3.1 \times 10^{-6} \mathrm{M} ; \mathrm{SE}, 5.4 \times 10^{-7} \mathrm{M} ; \mathrm{p}=0.04\right)$. Interestingly all isolates (including genotypes $\mathrm{C}$ and $\mathrm{P}$ ), whatever their site of collection, produced higher levels of $\mathrm{C}_{4}$-HSL than of 3-oxo- $\mathrm{C}_{12}$-HSL. The mean of the $\mathrm{C}_{4}$-HSL/ 3-oxo- $\mathrm{C}_{12}$-HSL ratios was 38.5 for the TA group compared to 5.1 for the ID group ( $\mathrm{p}=0.002$; Fig. 1C). Excluding the TA isolates with genotype $\mathrm{C}$ and $\mathrm{P}$ did not affect these results significantly. Therefore the relative amounts of AIs produced in vitro were significantly different between TA and ID isolates. The fact that all $P$. aeruginosa isolates tested were QS-proficient, i.e. able to produce both AIs in vitro, supports a role for QS during late stages of colonization of intubated patients both in the biofilm formed on intubation devices and in the lung.

\section{(ii) Production of QS-dependent virulence factors}

To further characterize the P. aeruginosa isolates, we determined their in vitro production of three virulence factors that depend upon an active QS-circuitry, namely, elastase, protease, and rhamnolipids [4]. We assayed the production of proteases and rhamnolipids using semi-quantita- 
Table 2: Characterization of $P$. aeruginosa isolates from intubated patients

\begin{tabular}{|c|c|c|c|c|c|c|c|c|c|c|}
\hline \multirow[t]{2}{*}{ Isolates } & \multirow[t]{2}{*}{ Patients } & \multirow[t]{2}{*}{ Genotype } & \multirow[t]{2}{*}{ Site of Isolation } & \multicolumn{2}{|c|}{ Production ${ }^{c}$ of } & \multirow{2}{*}{$\begin{array}{c}\text { Elastase }^{\mathrm{a}} \\
\left(\mathrm{OD}_{495} / \mathrm{OD}_{660}\right)\end{array}$} & \multicolumn{2}{|c|}{ Production $^{\mathrm{a}}$ of } & \multirow[t]{2}{*}{ Adhesion $^{\mathrm{a}}(\%)$} & \multirow[t]{2}{*}{ Biofilm ${ }^{a}(\%)$} \\
\hline & & & & Proteases & Rhamnolipids & & 3-oxo- $C_{12}-\mathrm{HSL}(\mu \mathrm{M})$ & $\mathrm{C}_{4}-\mathrm{HSL}(\mu \mathrm{M})$ & & \\
\hline $61 G 3^{d}$ & 8 & $D$ & TA & +++ & $\mathrm{BD}^{\mathrm{b}}$ & 0.5 & 0.51 & 15 & 88 & 31 \\
\hline $61 E 8$ & 8 & $D$ & TA & +++ & $\mathrm{BD}$ & 0.59 & 0.41 & 24 & 88 & II \\
\hline $60 \mathrm{~A} 3^{\mathrm{d}}$ & 8 & B & TA & +++ & + & 0.68 & 0.33 & 7.8 & 100 & 13 \\
\hline $60 \mathrm{~B} 5$ & 8 & $D$ & TA & +++ & $\mathrm{BD}$ & 0.65 & 0.36 & 5 & 139 & 33 \\
\hline 63E8 & 8 & B & ID & +++ & + & 0.3 & 1.3 & 2.4 & 116 & 83 \\
\hline $63 \mathrm{E} 9$ & 8 & B & ID & +++ & ++ & 0.34 & 2.5 & 1.1 & 111 & 105 \\
\hline $63 \mathrm{EIId}$ & 8 & B & ID & +++ & +++ & 0.29 & 0.19 & 2.9 & 105 & 89 \\
\hline $63 G 3$ & 8 & B & ID & +++ & + & 0.24 & 0.63 & 15 & 115 & 59 \\
\hline $63 \mathrm{G} 6$ & 8 & $D$ & ID & +++ & $\mathrm{BD}$ & 0.3 & 0.36 & 3 & 120 & 98 \\
\hline $63 \mathrm{G} 8$ & 8 & B & ID & +++ & ++ & 0.2 & 0.21 & 3.3 & 106 & 125 \\
\hline $63 \mathrm{H} 2$ & 8 & B & ID & +++ & +++ & 0.12 & 2.7 & 2.9 & 137 & 74 \\
\hline $62 \mathrm{~F} 2$ & 8 & $D$ & ID & +++ & $\mathrm{BD}$ & 0.32 & 0.37 & 3.1 & 99 & 10 \\
\hline $62 \mathrm{~F}^{\mathrm{d}}$ & 8 & $D$ & ID & +++ & + & 0.22 & 0.17 & 2.4 & 101 & 20 \\
\hline $62 \mathrm{G} 3$ & 8 & $D$ & ID & +++ & $B D$ & 0.3 & 0.29 & 3.3 & 110 & 25 \\
\hline $54 \mathrm{~A} 7$ & 12 & C & TA & +++ & ++ & 0.5 & 0.36 & 30 & 104 & 59 \\
\hline $54 \mathrm{~A} 8$ & 12 & B & TA & +++ & + & 0.63 & 0.41 & 19 & 115 & 49 \\
\hline $54 \mathrm{~A} 9$ & 12 & C & TA & +++ & +++ & 0.5 & 0.38 & 12 & 105 & 49 \\
\hline $54 \mathrm{BI}$ & 12 & C & TA & +++ & + & 0.64 & 0.77 & 30 & 99 & 60 \\
\hline $54 \mathrm{D} 5^{d}$ & 12 & B & TA & +++ & + & 0.48 & 0.35 & 14 & 116 & 50 \\
\hline $54 \mathrm{D} 6^{\mathrm{d}}$ & 12 & B & TA & +++ & +++ & 0.43 & 0.31 & 18 & 80 & 53 \\
\hline $54 \mathrm{EI}$ & 12 & $B$ & TA & +++ & ++ & 0.72 & 1 & 7.9 & 121 & 58 \\
\hline$\left.55 \mathrm{~A}\right|^{d}$ & 12 & B & ID & ++ & $B D$ & 0.19 & 2.6 & 2.1 & 116 & 78 \\
\hline $55 \mathrm{~A} 2$ & 12 & B & ID & ++ & + & 0.27 & 1.2 & 1.3 & 122 & 75 \\
\hline $55 \mathrm{~A} 5$ & 12 & B & ID & ++ & ++ & 0.26 & 2.5 & 2.8 & 137 & 102 \\
\hline 55D2 & 12 & B & ID & ++ & + & 0.27 & 2 & 3.4 & 118 & 68 \\
\hline 55E4 & 12 & $B$ & ID & ++ & ++ & 0.31 & 2.5 & 2.7 & 115 & 88 \\
\hline $55 \mathrm{~F}^{\mathrm{d}}$ & 12 & $B$ & ID & ++ & +++ & 0.22 & 2.5 & 2.2 & 101 & 59 \\
\hline $55 \mathrm{G} 2$ & 12 & $B$ & ID & ++ & ++ & 0.17 & 4 & 2 & 117 & 84 \\
\hline $55 \mathrm{G} 4$ & 12 & $B$ & ID & ++ & + & 0.19 & 1.3 & 1.6 & 112 & 103 \\
\hline $55 \mathrm{~A} 6$ & 12 & $B$ & ID & ++ & +++ & 0.25 & 2.1 & 3.4 & 126 & 109 \\
\hline $56 \mathrm{Al}$ & 13 & B & TA & +++ & ++ & 0.64 & 0.44 & 6.4 & 85 & 46 \\
\hline $59 \mathrm{~B} 3$ & 13 & $C$ & TA & +++ & ++ & 0.45 & 0.3 & 7.9 & 88 & 39 \\
\hline $59 \mathrm{~B} 4^{\mathrm{d}}$ & 13 & $B$ & TA & +++ & ++ & 0.47 & 0.16 & 9.5 & 83 & 48 \\
\hline $59 \mathrm{Al}$ & 13 & B & TA & +++ & +++ & 0.52 & 0.13 & 9.3 & 99 & 38 \\
\hline $59 \mathrm{~B} 6$ & 13 & $P$ & TA & +++ & ++ & 0.45 & 0.28 & 13.5 & 83 & 41 \\
\hline $59 \mathrm{Cl}$ & 13 & $P$ & TA & +++ & +++ & 0.52 & 0.27 & 11.3 & 106 & 77 \\
\hline $59 C 2$ & 13 & $P$ & TA & +++ & + & 0.47 & 0.33 & 13.3 & 101 & 59 \\
\hline $63 \mathrm{Al}$ & 13 & B & ID & +++ & ++ & 0.23 & 1.4 & 1.8 & 114 & 91 \\
\hline $63 \mathrm{~A}^{\mathrm{d}}$ & 13 & B & ID & +++ & +++ & 0.3 & 0.33 & 3.1 & 137 & 77 \\
\hline $6|A| 2^{d}$ & 13 & $B$ & ID & +++ & +++ & 0.15 & 2.6 & 2.2 & 129 & 90 \\
\hline $61 \mathrm{GI} 2$ & 13 & B & ID & +++ & ++ & 0.11 & 2.7 & 2.4 & 121 & 87 \\
\hline $62 C 2$ & 13 & $B$ & ID & +++ & ++ & 0.15 & 2.6 & 3.1 & 121 & 97 \\
\hline $62 C 3$ & 13 & B & ID & +++ & +++ & 0.08 & 1.3 & 3.3 & 143 & 86 \\
\hline
\end{tabular}

a Values are mean of three independent experiments with a standard deviation of $<10 \%$. $\mathrm{b} \mathrm{BD}$, below detection.

c +++, high level; ++, intermediate level; +, low level.

$\mathrm{d}$ las $R$ and $r$ IR genes sequenced

tive plate assays. Important fluctuations in the production of rhamnolipids were observed (Table 2). This finding was not surprising as we had previously found fluctuations among QS-associated phenotypes occurring during the colonization of intubated patients [18]. LasB elastase is the most potent elastase produced by $P$. aeruginos $a$ and is one of the major virulence factors controlled by QS [4]. We quantified the in vitro elastase production of the clini- cal isolates by means of the Elastin Congo Red assay at the same point in the growth curve (early stationary phase) as for determination of AIs production. For each patient the isolates obtained from the TA displayed higher elastolytic activities than those obtained from the ID (Fig. 2A). When the isolates were grouped by site of isolation, the mean elastase production was higher in the TA group $(0.57 ; \mathrm{SE}$, $0.02)$ than in the ID group (0.23; SE, 0.02; $p<0.001$; Fig. 
A

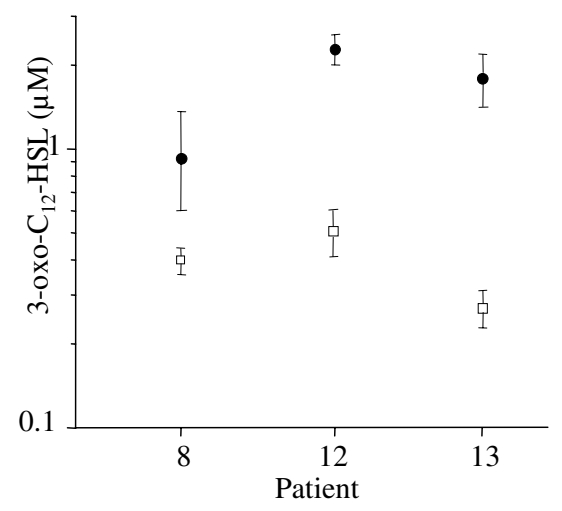

B

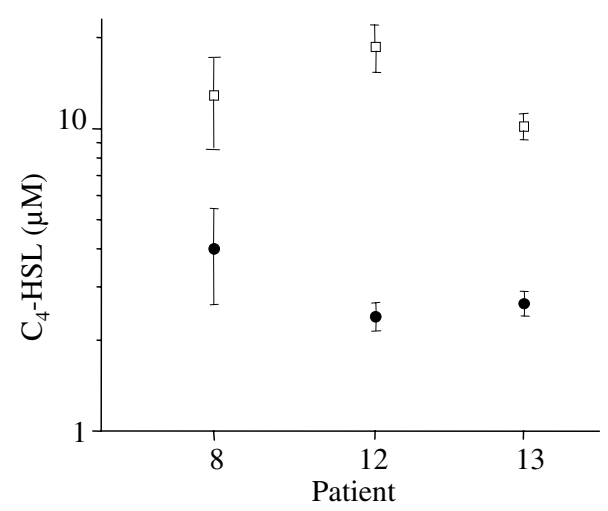

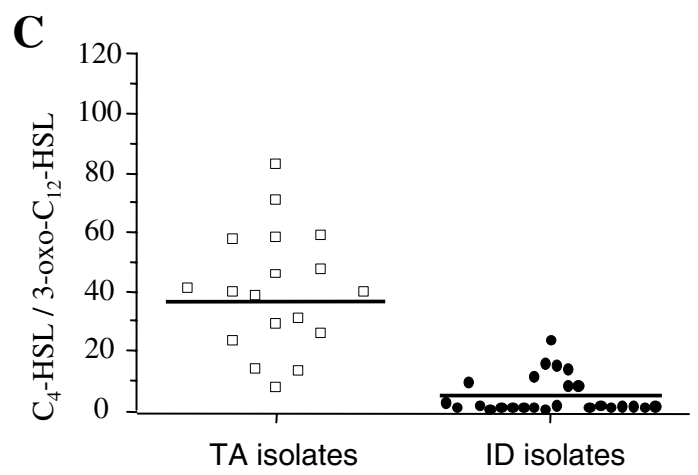

Figure I

Autoinducer production of $P$. aeruginosa isolates from tracheal aspirates and intubation devices. 3-oxo- $\mathrm{C}_{12}-\mathrm{HSL}$ (A) and $\mathrm{C}_{4}-\mathrm{HSL}(\mathrm{B})$ production by $P$. aeruginosa isolates recovered from tracheal aspirates (open squares, TA isolates) and intubation devices (plain circles, ID isolates) of 3 colonized patients $(8,12$ and I3). The production of the two autoinducers was determined in culture supernatants by specific bioassays. Error bars correspond to the standard errors of the means. (C) Ratios of $\mathrm{Al}$ concentrations $\left(\mathrm{C}_{4}-\mathrm{HSL} / 3-0 \times 0-\mathrm{C}_{12}-\mathrm{HSL}\right)$ produced by 18 isolates recovered from tracheal aspirates and 25 isolates recovered from intubation devices. The horizontal line indicates the mean of the ratios.

2B). These results did not differ when all the genotypes were included in the TA isolates group. These results suggest that $P$. aeruginosa strains originating from the lungs of intubated patients produce higher amounts of elastase than isolates that were resident inside the biofilm on the intubation device.

\section{(iii) Adhesion and biofilm formation capacity}

QS has been suggested to be involved in the formation and differentiation of biofilms $[7,8,13]$. The impact of the type of surface and medium used in biofilm formation assays appears to influence the relationship between QS and biofilm formation [20]. We therefore decided to measure biofilm formation with our well-established static system using sterile PVC coupons obtained from intubation devices [8]. In our opinion this model simu- lates the best the conditions found on intubation devices in patients. Both adhesion and biofilm formation capacities were compared to the laboratory strain $P$. aeruginosa PT5 (100\%). For each individual patient $P$. aeruginosa isolates recovered from the surface of the ID adhered more efficiently than their counterparts collected from the TA (Fig. 2C). When all the isolates were grouped by site of isolation the mean adhesion capacity was slightly increased in the ID group without reaching statistical significance $(118.0 \%$; SE, $4.0 \%)$ as compared to the TA group (101.3\%; SE, 5.2\%; $\mathrm{p}=0.19$; Fig. $2 \mathrm{D}$ ). The ID isolates for each patient demonstrated a greater ability to form biofilm than their TA counterparts (Fig. 2E). This difference was statistically significant when the strains were grouped according to their site of isolation (ID isolates: 79.3\%; SE, 6.3\%, TA isolates: $39.1 \%$; SE, 9.8\% $\mathrm{p}=0.01$, 
A

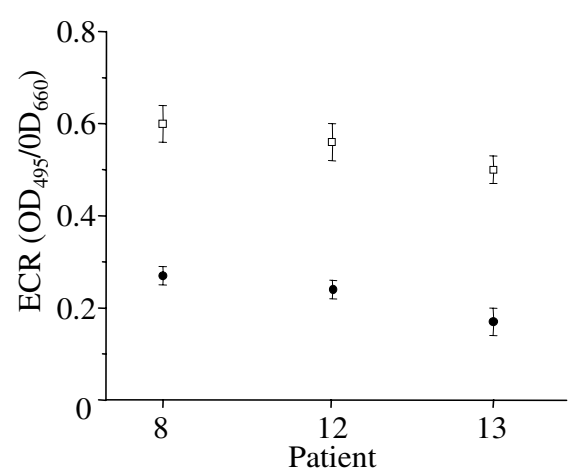

C

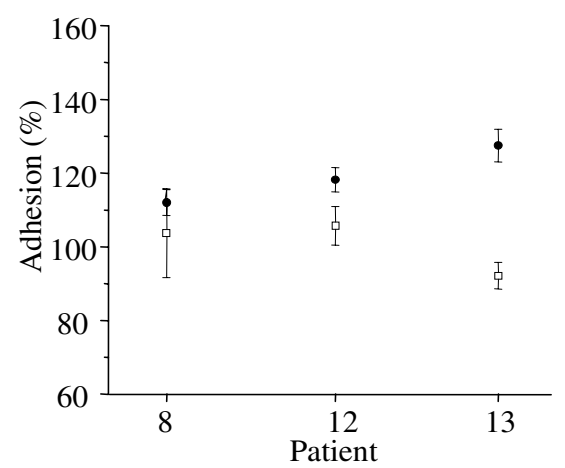

$\mathbf{E}$

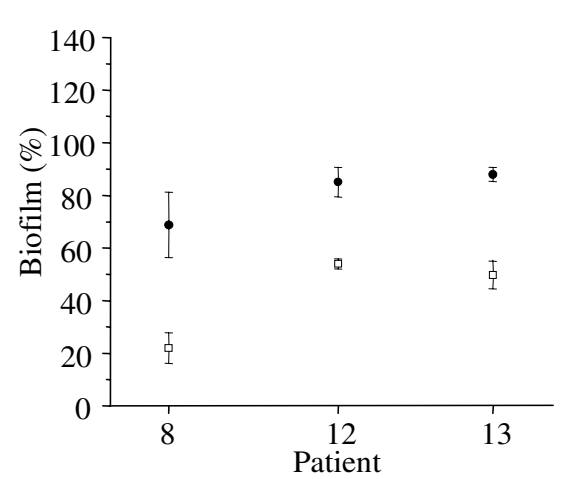

B

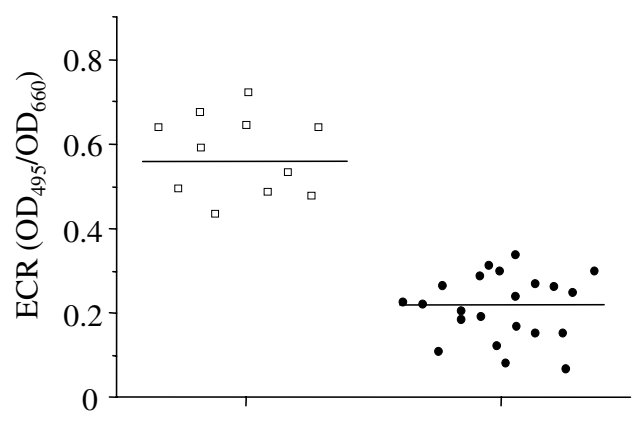

TA isolates

ID isolates

D

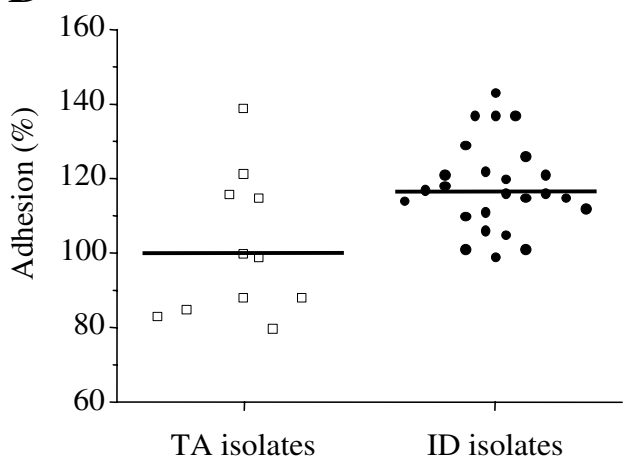

F

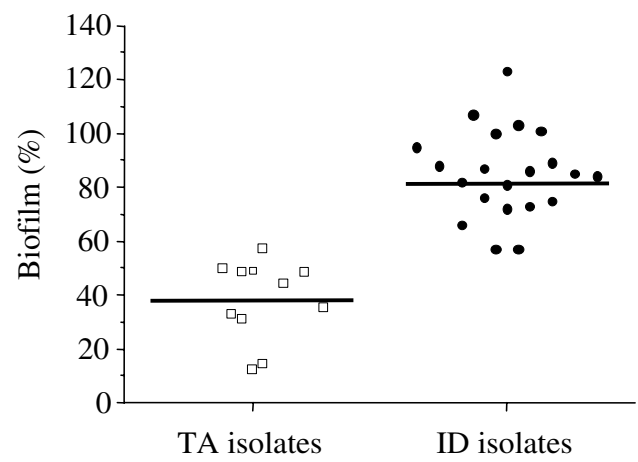

\section{Figure 2}

Quorum-sensing dependent phenotypes of $P$. aeruginosa isolates from tracheal aspirates and intubation devices. Elastase production ( $A$ and $B$ ), adhesion capacity ( $C$ and $D)$ and biofilm formation ( $E$ and $F)$ by $P$. aeruginosa isolates recovered from tracheal aspirates (open squares, TA isolates) and intubation devices (plain circles, ID isolates). Elastolytic activities were determined by ECR assays and expressed as the OD measured at $495 \mathrm{~nm}$ per unit of OD $660 \mathrm{~nm}$. The adhesion capacities and biofilm formation were expressed as the percentage relative to the level obtained with the wild-type $P$. aeruginosa strain PT5. (A, C and E) Results individualized for each patient $(8,12$ and 13$)$, error bars correspond to the standard errors of the means. (B, D and F) Mean values and variances for II tracheal aspirate isolates and 25 isolates recovered from the intubation devices. For each individual isolate the determinations were performed twice in triplicates. 
Fig. 2F). Again these results were not affected when genotypes $\mathrm{C}$ and $\mathrm{P}$ were included in the TA group. These observations indicate that $P$. aeruginosa isolates originating from the biofilm of intubation devices tend to adhere more efficiently and have higher biofilm production capacities than their counterparts isolated from the lungs.

\section{Correlations between autoinducer production and quorum-sensing dependent phenotypes}

(I) Correlations between autoinducer and elastase production

In vitro, the production of elastase is under the joint control of both the las and $r h l$ QS-systems $[4,9]$. In sputum of CF patients the expression of las $R$ has been correlated with the accumulation of lasB transcripts [21]. Other investigators have described a weak correlation between the in vitro transcription levels of lasR and lasB in 50\% of environmental and clinical isolates [22]. We wondered whether the production of elastase would be correlated with the production of autoinducers. For these analyses we included only genotypes B and D, which were present in both TA and ID isolates. We observed a trend for a positive correlation between 3 -oxo- $\mathrm{C}_{12}$-HSL and elastase production for the TA group $(\mathrm{r}=0.58 ; \mathrm{p}=0.06)$. This positive correlation became statistically significant when genotypes $\mathrm{C}$ and $P$ were included $(r=0.63, p=0.006$; Fig. $3 \mathrm{~A})$. In contrast for ID isolates we observed a statistically significant negative correlation between elastase and 3-oxo- $\mathrm{C}_{12}$-HSL production $(\mathrm{r}=-0.41, \mathrm{p}=0.04)$. Furthermore, $\mathrm{C}_{4}$-HSL production was not correlated with elastase activity, whatever the isolate group studied (TA isolates: $\mathrm{r}=-0.38, \mathrm{p}=$ 0.25 and ID isolates: $r=0.02, p=0.70$ ). These results suggest that the level of 3-oxo- $\mathrm{C}_{12}$-HSL is positively correlated to elastase production for isolates from tracheal aspirates of colonized patients, but not for $P$. aeruginosa isolates from biofilms covering the intubation devices.

\section{(II) Correlation between autoinducer production, adhesion and biofilm formation capacities}

We then examined correlations between autoinducer production and adhesion capacity. There was a weak, statistically not significant, correlation between 3-oxo- $\mathrm{C}_{12}$-HSL production and adhesion capacity for isolates from the ID group $(\mathrm{r}=0.30, \mathrm{p}=0.14)$ (Fig. $3 \mathrm{~B})$. No such correlation was found for isolates from the TA group $(\mathrm{r}=0.33, \mathrm{p}=$ 0.32 ), even when genotypes $\mathrm{C}$ and $\mathrm{P}$ were included in the analysis $(\mathrm{r}=0.30, \mathrm{p}=0.22)$. We found no correlation between $\mathrm{C}_{4}$-HSL production and adhesion for both ID isolates $(\mathrm{r}=0.0 ; \mathrm{p}=0.99)$ and TA isolates $(\mathrm{n}=11: \mathrm{r}=0.34$; $\mathrm{p}=0.30$, and $\mathrm{n}=18: \mathrm{r}=0.16 ; \mathrm{p}=0.53)$.

Similarly we observed a weak, statistically not significant, correlation between 3-oxo- $\mathrm{C}_{12}$-HSL and biofilm production for isolates of the ID group $(r=0.33, p=0.11$, Fig. $3 \mathrm{C})$, but not for those recovered from TA $(\mathrm{r}=0.25, \mathrm{p}=$ 0.46 ), even after inclusion of genotypes $C$ and $P$ in the analysis $(\mathrm{r}=0.17, \mathrm{P}=0.49)$. There was no correlation between $\mathrm{C}_{4}$-HSL and biofilm production for the ID $(\mathrm{r}=$ $0.18, \mathrm{p}=0.31)$, and TA isolates $(\mathrm{r}=-0.18, \mathrm{p}=0.60)$, despite the inclusion of genotypes $\mathrm{C}$ and $\mathrm{P}(\mathrm{r}=0.16, \mathrm{p}=$ $0.52)$. Together these observations suggest that the production of 3-oxo- $\mathrm{C}_{12}$-HSL but not of $\mathrm{C}_{4}$-HSL, might be associated with in vitro adherence and biofilm formation capacities among isolates recovered from the biofilm on intubation devices.

\section{Discussion}

Respiratory tract colonization of intubated patients by $P$. aeruginosa is initiated by the colonization of the intubation device by bacteria either originating from the digestive flora of the patient (endogenous acquisition) or transmitted via handling of the device by health care workers (exogenous acquisition) [23]. This colonization requires efficient bacterial adherence to the inert surface and the formation of a biofilm [3]. P. aeruginosa then reach the respiratory tract either by leakage around the cuff of the intubation device, by shearing of secretions containing embedded bacteria from the device during the inspiratory air flow, or by contamination and direct inoculation of the respiratory tract by suction tubes introduced through the intubation device by health care workers [2325].

Both in vitro studies and animal models have suggested that QS plays a major role in the virulence of $P$. aeruginosa [11]. However in situ and in patient data concerning the potential role of QS during colonization and infection by $P$. aeruginosa in humans remain scarce. QS-activity has been linked to the detection of $P$. aeruginosa AIs in the lungs of cystic fibrosis patients [13-16], as well as in lung transplanted patients [17]. So far studies have only shown that most of the isolates originating from colonized intubated patients are QS-proficient $[18,22]$.

In the present study we show that the two $P$. aeruginosa autoinducers, 3-oxo- $\mathrm{C}_{12}$-HSL and $\mathrm{C}_{4}$-HSL, can be detected in situ in biofilms covering intubation devices retrieved from patients colonized by $P$. aeruginosa. Moreover all $P$. aeruginosa isolates collected either from these biofilms or from tracheal aspirates produced these AIs in vitro. Whereas 3-oxo- $\mathrm{C}_{12}$-HSL has been previously shown to play a role in the differentiation of $P$. aeruginosa biofilms $[7,26], \mathrm{C}_{4}$-HSL seems to be important during the maturation stage of biofilm development [27], for the total amount of biofilm formed [8], and for the maintenance of biofilm architecture [28]. In our study, isolates recovered from the biofilm of intubation devices produced higher levels of $\mathrm{C}_{4}$-HSL than 3-oxo- $\mathrm{C}_{12}$-HSL in vitro. Previous observations have suggested that $\mathrm{C}_{4}$-HSL is produced in higher quantities than 3 -oxo- $\mathrm{C}_{12}$-HSL in $P$. aeruginosa biofilms in the lungs of CF patients $[13,14]$. Singh et al. have 

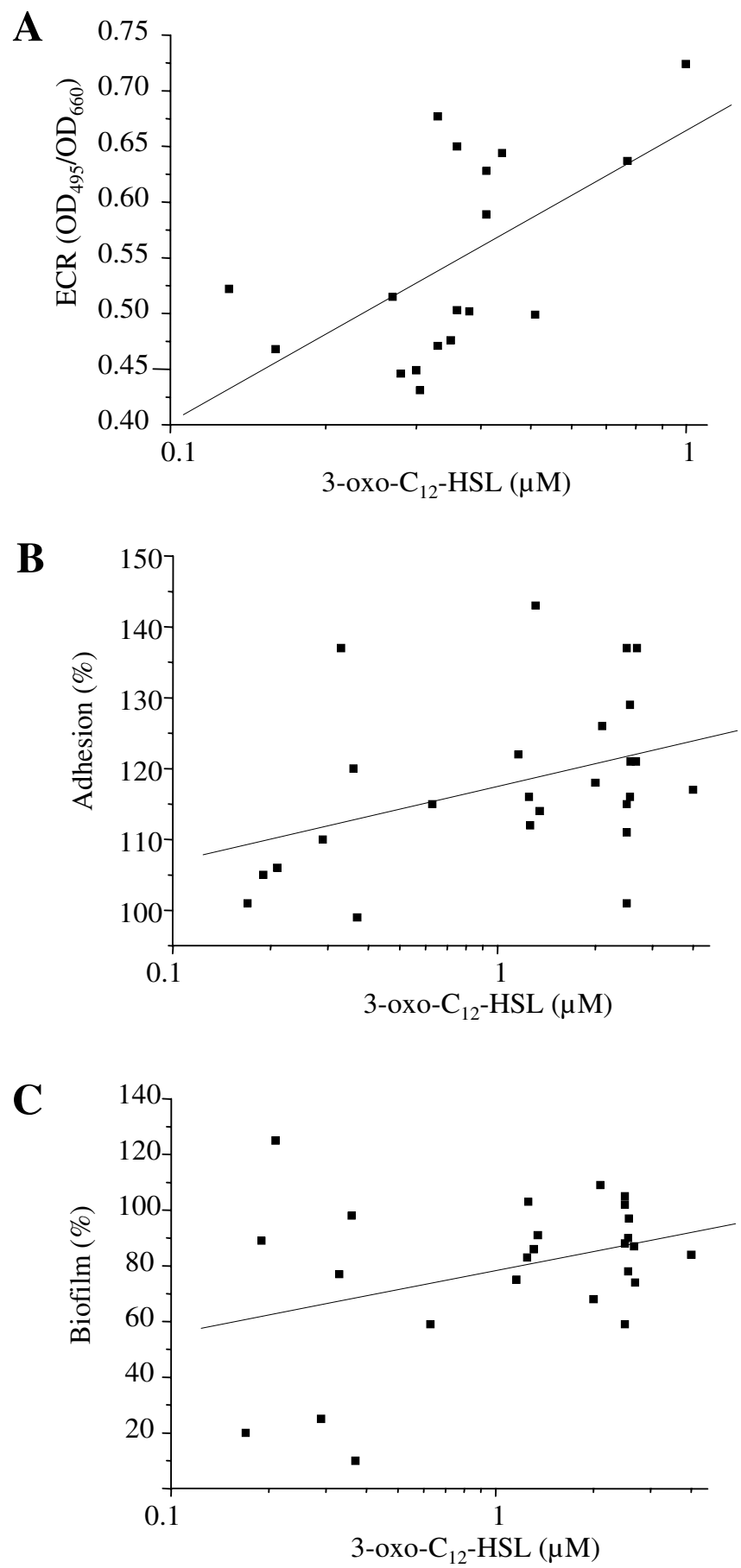

\section{Figure 3}

Correlations between autoinducer production and quorum-sensing dependent phenotypes. Relations between levels of 3-oxo- $C_{12}-\mathrm{HSL}$ and elastase production by $P$. aeruginosa isolates recovered from tracheal aspirations (A), and adhesion capacity $(B)$ as well as biofilm formation $(C)$ by $P$. aeruginosa isolates recovered from intubation devices. (A) For each isolate the production of 3-oxo- $C_{12}-\mathrm{HSL}$ and elastase was measured in aliquots taken at the same time during the growth curve, and plotted against each other. (B and $C$ ) For each isolate aliquots for 3-oxo- $C_{12}-$ HSL determinations were taken at an identical time during the growth curve. Adhesion capacities and biofilm formation are expressed compared to wild type strain PT5 $(100 \%)$. Each determination is the mean of two independent experiments performed in triplicate. 
even suggested that this AI ratio might serve as a biomarker for the biofilm mode of growth, as the mucoid isolates from the sputum of CF patients inverted their AI ratio when sub-cultured in liquid medium [13]. In contrast, in our study a higher level of $\mathrm{C}_{4}$-HSL as compared to 3-oxo$\mathrm{C}_{12}$-HSL was observed when isolates were grown in liquid cultures, suggesting that this ratio is not useful as a biomarker for biofilm growth for these isolates. None of the isolates collected from our patients had a mucoid phenotype. This discrepancy could therefore be explained by inherent differences in biofilm development patterns between mucoid and non-mucoid strains. So far there is no evidence that non-mucoid $P$. aeruginos a colonizing the lung of intubated patients grows in biofilms. Such a hypothesis deserves further investigations.

Autoinducers have been previously recovered from biofilms formed on urinary tract catheters [19] and our results show for the first time that QS-signaling molecules are also produced in biofilms covering intubation devices. Whether the local concentrations of AIs on the intubation devices that we measured are physiologically relevant and are sufficient to activate the expression of QS-dependent genes remains speculative. However microarray analyses have shown that QS is a continuum and that the expression of some genes is already activated even at low AI concentrations [9]. It is therefore likely that even low concentrations of AIs on the intubation devices are physiologically relevant.

Intriguingly, the in vitro production of both AIs varied with the site of collection. Isolates from tracheal aspirates produced higher levels of $\mathrm{C}_{4}$-HSL but lower levels of 3oxo- $\mathrm{C}_{12}$-HSL than their genotypically identical counterparts isolated from intubation devices, even after several in vitro passages. This observation suggests that different microenvironments select $P$. aeruginosa isolates with various AI production capacities. Moreover the production of elastase, and the capacity to adhere to an inert surface and to produce a biofilm also varied with the site of isolation. Tracheal aspirate isolates produced higher levels of elastase, but were less able to adhere and produce biofilm than their counter-parts recovered from intubation devices. LasB elastase is one of the major virulence factors controlled by the P. aeruginosa QS-circuit [4]. In vitro its production is regulated by the QS-circuit and depends mainly on the production of 3 -oxo- $\mathrm{C}_{12}$-HSL $[9,10]$. LasB elastase is believed to allow $P$. aeruginosa to invade surrounding tissues by its broad range enzymatic activity and to facilitate blood stream invasion by degradation of elastin fibers in the lamina propria of blood vessels [4].

The observed differences in phenotypes between isolates obtained from tracheal aspirates, compared to those from the intubation devices, make sense. Isolates growing in the biofilm on intubation devices might not invest energy in producing elastase, but might be primed to adhere and form biofilms, whereas isolates growing in the lungs might find an advantage in producing elastase. For tracheal aspirate isolates, levels of 3 -oxo- $\mathrm{C}_{12}$-HSL production correlated positively with the capacity to produce elastase. In contrast for isolates originating from the intubation device, 3-oxo- $\mathrm{C}_{12}$-HSL levels did not correlate with elastase production, but correlated weakly with the capacity to adhere and to form biofilms on inert surfaces. These observations suggest that the previously described control of LasR on elastase production might not apply to all isolates depending on the site they were collected from. It seems that the microenvironment on the intubation devices selects for phenotypes that produce high levels of 3-oxo- $\mathrm{C}_{12}$-HSL but without concomitant increased elastase production. In contrast the lower lung environment seems to select for isolates that produce less 3-oxo$\mathrm{C}_{12}$-HSL but with a positive control of this AI on elastase production. Two of our patients (12 and 13) received antimicrobial therapies during their mechanical ventilation. We can therefore not exclude that different concentrations of these drugs at the two sites might have selected different phenotypes. However this seems unlikely as isolates of patient 8 presented the same differences in phenotype in the absence of any exposure to antimicrobial therapies.

We detected no correlations between the levels of $\mathrm{C}_{4}$-HSL production and elastase activity, adhesion or biofilm formation. Strikingly, these phenotypes remained stable for each isolate independently of its origin even after several in vitro passages. This suggests that mutations in specific regulators, that affect the production of AIs and the expression of QS-dependent phenotypes might be selected in particular microenvironments. Indeed las $R$ and rhlR mutants of $P$. aeruginosa strains isolated from intubated patients have been previously described [18]. Such mutations influence the bacteria capacity to produce AIs, and are expected to affect QS-dependent phenotypes. We therefore sequenced both lasR and $r h R$ in 6 TA and 6 ID isolates (Table 2). None of them harbored mutations compared to the wild type strain PAO1 (data not shown). This explains why all the isolates analyzed in the present study were QS-proficient. Phenotypic variations not linked to QS but also influencing biofilm formation have been described in $P$. aeruginosa isolates from CF patients [29]. The nature of the mutational events possibly selected either during biofilm growth on intubation devices, or inside the lung are presently under investigation. The identification of these events would have major implications for our understanding of bacterial selection in specific environments and the dynamics of bacterial populations. 
QS-inhibition has been suggested as a new therapeutical approach against $P$. aeruginosa infections. For instance macrolides interfere with the production of AIs $[8,30]$ and were shown to retard biofilm formation [31]. Our result might be important if QS-inhibitors that interfere with the production and/or activity of one, or both, of the autoinducers are used in the prevention or treatment of $P$. aeruginosa VAP. Indeed, our data suggest that inhibition of QS might have different effects on $P$. aeruginosa isolates depending on their microenvironnement.

\section{Conclusion}

Our study was limited to the analysis of three patients; therefore it is difficult to draw general conclusions from our observations. However the results were consistent between these patients and reached statistical significance despite the small number. Our results showed that during colonization of intubated patients $P$. aeruginosa autoinducers are produced in the biofilms covering the intubation devices. The capacity to produce autoinducers and the expression of QS-dependent phenotypes vary with the site of isolation. Further studies will be required to investigate the mechanism that led to selection of specific phenotypes in a particular microenvironment directly in vivo and to determine how this impacts the use of anti-quorum-sensing strategies.

\section{Methods}

\section{Patient population and clinical sample collection}

We collected the intubation devices of eight patients known to be colonized by $P$. aeruginosa and hospitalized in the surgical intensive care service of the University Hospital Geneva. All patients, except patient 14, have been described previously (Table 1) [18]. Following extubation the endotracheal tubes were wrapped in a sterile cloth and transported without delay to the laboratory were they were stored at $-70^{\circ} \mathrm{C}$ until use. Sterile cotton swabs were used to detach bacteria embedded in biofilm formed on the cuff, on the exterior surface of the intubation device (ID). Pseudomonas isolates were identified on selective Cetrimide agar plates. In order to avoid compiling identical $P$. aeruginosa isolates, we collected individual clones based on morphologic differences of their respective colony forming units (CFU). A total of 25 ID isolates were collected from patients 8,12 and 13 , and stored at $-70^{\circ} \mathrm{C}$ (Table 2).

We obtained tracheal aspirates by suctioning secretions with a sterile tube introduced deeply inside the lower respiratory tract through the intubation device from three patients (patients 8, 12 and 13) either on the day before, or on the day of extubation. The tracheal aspirates (TA) were plated on selective agar plates (Cetrimide $0.03 \%$ ) in order to identify Pseudomonas isolates [14]. Similarly to ID isolates, special care was taken to select isolates with dif- ferent morphologic phenotypes according to their CFUs. A total of 18 different TA isolates were identified and stored at $-70^{\circ} \mathrm{C}$ (Table 2).

For further assays both ID and TA isolates were taken from the frozen stocks and grown in liquid cultures.

\section{Media and culture conditions}

Cultures for extraction of cell-to-cell signaling molecules and production of elastase were grown in Luria-Bertani (LB) broth. M63 medium [32] was used for bacterial adhesion assays and AP medium [33] was used for biofilm formation assays. No differences in growth rates were observed between the strains in these media.

\section{Extraction and quantification of acylated homoserine lactones (Als) from intubation devices and liquid cultures}

Previous studies have suggested that secretions colonized by bacteria accumulate above the cuff of intubation devices and form biofilms [34-36]. Leakage of bacteria around the cuff might play a major role in the development of ventilator-associated pneumonia [25,37]. Consequently, we selected the cuff of the intubation devices for the quantification of AIs. To extract AIs; cuffs were aseptically cut off the intubation devices, incubated for $30 \mathrm{~min}$ utes at $37^{\circ} \mathrm{C}$ in $5 \mathrm{ml}$ sterile saline containing $0.025 \%$ dithiothreitol (DTT) to resuspend the biofilms formed on the cuff, and extracted twice by the addition of 1 volume of acidified ethyl acetate for 5 minutes at $-20^{\circ} \mathrm{C}$. To extract AIs from liquid cultures of both ID and TA isolates, the strains were incubated in $\mathrm{LB}$ broth at $37^{\circ} \mathrm{C}$ with shaking. Aliquots of filtered culture supernatants, taken after 8 hours of growth (early stationary phase), were subjected to 2 extractions in 1 volume of acidified ethyl acetate and stored at $-70^{\circ} \mathrm{C}$. Aliquots of the extracts obtained from the cuffs and liquid cultures of ID and TA isolates were evaporated under nitrogen gas and the concentrations of 3oxo- $\mathrm{C}_{12}$-HSL and $\mathrm{C}_{4}$-HSL determined using the reporter

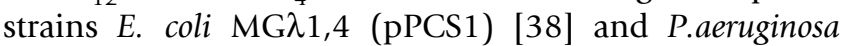
PAO-JP2 (pECP61.5) [39] respectively. For each determination standard curves were obtained with the wild type strain PAO1. The amount of AIs recovered from the intubation devices was expressed as nmoles/cuff.

\section{Determination of bacterial genotype}

Bacterial strains were genotyped by Random Amplified Polymorphic DNA (RAPD) analysis as previously described using the Ready-to-Go Kit (Amersham) [18] using primer 208 (ACGGCCGACC) [40].

\section{Production of protease, rhamnolipids and elastase}

Total extracellular protease [41] and rhamnolipid [42] production of both ID and TA isolates were determined semi-quantitatively by agar plate assays. Elastase production was quantified using the Elastin Congo Red elastoly- 
sis assay $[38,41]$. Culture supernatants were collected at the same point in the bacterial growth curve as for $\mathrm{AI}$ extraction.

\section{Assessment of bacterial adhesion and biofilm formation assay}

Adhesion capacity was measured for both ID and TA isolates as the ability of bacteria to adhere to the wells of 96well microtiter plates. The assay was performed as previously described [18]. Results were expressed as percent adhesion with respect to the PT5 wild type strain. The ability of bacteria to form biofilm in vitro was determined in a static model as previously described [8]. Briefly, overnight LB cultures of ID and TA isolates were diluted to an $\mathrm{OD}_{660}$ of 0.5 and incubated for a further 6 hours at $37^{\circ} \mathrm{C}$ with shaking until cells had entered early stationary phase. Sterile calibrated coupons of PVC tracheal tubing were immersed in the suspension and incubated statically at $37^{\circ} \mathrm{C}$ for $1 \mathrm{~h}$, then the PVC coupons were transferred to 6 well cell culture plates and incubated statically at $37^{\circ} \mathrm{C}$ for $72 \mathrm{~h}$ in AP medium. The extent of biofilm formation was measured using crystal violet staining [43]. Results were expressed as percent biofilm formation with respect to the PAO1 wild type strain.

\section{Statistical analysis}

We used the Student's t test to compare mean production of AIs and virulence factors by isolates from tracheal aspirates (TA) and the cuff of the intubation device (ID). Correlations between AIs production and QS-dependent phenotypes were calculated using a robust estimator of the Pearson's correlation coefficient. To account for the correlation among multiple observations in the same patient, standard errors and p values were computed using a first-order Taylor-series linearization method. All analyses were conducted using Stata 6.0 statistical software (StataCorp, 1999). $\mathrm{p}<0.05$ was considered statistically significant.

\section{Authors' contributions}

SFB carried out the experiments and drafted the manuscript. CE conducted the statistical analysis. TK participated in the design of the study and participated in the analysis of the results. JAR organized the sample collection. CVD conceived the study, supervised the experiments and their analysis, and wrote the final manuscript. All authors read and approved the final manuscript.

\section{Acknowledgements}

We would like to thank J. Pugin, and B. Ricou for supplying us with the intubation devices necessary for the study, P. Wood for helping during the preparation of the manuscript and R. Comte for technical assistance. This work was supported by grants from the Programme Commun de Recherche en Génie Biomédical, Genève, Lausanne 1999-2002 and from the Swiss National Science Foundation (323I-5I940.97 and 3200-052 I89.97) to CVD.

\section{References}

I. Dunn M, Wunderink RG: Ventilator-associated pneumonia caused by Pseudomonas infection. Clin Chest Med 1995, 16:95.

2. Levine SA, Niederman MS: The impact of tracheal intubation on host defenses and risks for nosocomial pneumonia. Clin Chest Med 1991, I2(3):523.

3. Costerton JW, Stewart PS, Greenberg EP: Bacterial biofilms: a common cause of persistent infections. Science 1999, 284(54 | 8): $13 \mid 8$.

4. Van Delden C, Iglewski BH: Cell-to-cell signaling and Pseudomonas aeruginosa infections. Emerg Infect Dis 1998, 4:55।.

5. Latifi A, Winson MK, Foglino M, Bycroft BW, Stewart GS, Lazdunski A, Williams P: Multiple homologues of LuxR and Luxl control expression of virulence determinants and secondary metabolites through quorum sensing in Pseudomonas aeruginosa PAO I. Mol Microbiol 1995, I 7:333.

6. Passador L, Cook JM, Gambello MJ, Rust L, Iglewski BH: Expression of Pseudomonas aeruginosa virulence genes requires cellto-cell communication. Science 1993, 260(5 I I I): I I 27.

7. Davies DG, Parsek MR, Pearson JP, Iglewski BH, Costerton JW, Greenberg EP: The involvement of cell-to cell signals in the development of bacterial biofilm. Science 1998, 280:295.

8. Favre-Bonté S, Köhler T, Van Delden C: Biofilm formation by Pseudomonas aeruginosa : role of the C4-HSL cell-to-cell signal and inhibition by azithromycin . J Antimicrob Chemother 2003, 52:598-604.

9. Schuster M, Lostroh CP, Ogi T, Greenberg EP: Identification, timing, and signal specificity of Pseudomonas aeruginosa quorum-controlled genes: a transcriptome analysis. I Bacteriol 2003, I 85(7):2066.

10. Wagner VE, Bushnell D, Passador L, Brooks Al, Iglewski BH: Microarray analysis of Pseudomonas aeruginosa quorum-sensing regulons: effects of growth phase and environment. J Bacteriol 2003, 185:2080.

II. Rumbaugh KP, Griswold JA, Hamood AN: The role of quorum sensing in the in vivo virulence of Pseudomonas aeruginosa. Microbes Infect 2000, 2: I72I.

12. Geisenberger O, Givskov M, Riedel K, Hoiby N, Tümmler B, Eberl L: Production of $\mathbf{N}$-acyl-L-homoserine lactones by $\mathbf{P}$. aeruginosa isolates from chronic lung infections associated with cystic fibrosis. FEMS Microbiol Lett 2000, I84:273.

13. Singh PK, Schaefer AL, Parsek MR, Moninger TO, Welsh MJ, Greenberg EP: Quorum-sensing signals indicate that cystic fibrosis lungs are infected with bacterial biofilms. Nature 2000 , 407:762.

14. Favre-Bonté S, Pache JC, Robert J, Blanc D, Pechère JC, Van Delden $\mathrm{C}$ : Detection of Pseudomonas aeruginosa cell-to-cell signals in lung tissue of cystic fibrosis patients. Microb Pathog 2002, 32(3): 143.

15. Erickson DL, Endersby R, Kirkham A, Stuber K, Vollman DD, Rabin HR, Mitchell I, Storey DG: Pseudomonas aeruginosa quorumsensing systems may control virulence factor expression in the lungs of patients with cystic fibrosis. Infect Immun 2002, 70(4): 1783.

16. Middleton B, Rodgers HC, Camara M, Knox AJ, Williams P, Hardman $A$ : Direct detection of $\mathbf{N}$-acylhomoserine lactones in cystic fibrosis sputum. FEMS Microbiol Lett 2002, 207(I):I.

17. Ward C, Camara M, Forrest I, Rutherford R, Pritchard G, Daykin M, Hardman A, de Soyza A, Fisher AJ, Williams P, Corris PA: Preliminary findings of quorum signal molecules in clinically stable lung allograft recipients. Thorax 2003, 58(5):444.

18. Denervaud V, TuQuoc P, Blanc D, Favre-Bonté S, Krishnapillai V, Reimmann C, Haas D, Van Delden C: Characterization of cell-tocell signaling-deficient Pseudomonas aeruginosa strains colonizing intubated patients. J Clin Microbiol 2004, 42(2):554.

19. Stickler DJ, Morris NS, McLean RJ, Fuqua C: Biofilms on indwelling urethral catheters produce quorum-sensing signal molecules in situ and in vitro. Appl Environ Microbiol 1998, 64:3486.

20. Shrout JD, Chopp DL, Just CL, Hentzer M, Givskov M, Parsek MR: The impact of quorum sensing and swarming motility on Pseudomonas aeruginosa biofilm formation is nutritionally conditional. Mol Microbiol 2006.

21. Storey DG, Ujack EE, Rabin HR, Mitchell I: Pseudomonas aeruginosa las $R$ transcription correlates with the transcription of las $A$, lasB, and toxA in chronic lung infections associated with cystic fibrosis. Infect Immun 1998, 66(6):2521. 
22. Cabrol S, Olliver A, Pier GB, Andremont A, Ruimy R: Transcription of quorum-sensing system genes in clinical and environmental isolates of Pseudomonas aeruginosa. J Bacteriol 2003, I 85:7222.

23. Chastre J, Fagon JY: Ventilator-associated pneumonia. Am J Respir Crit Care Med 2002, I 65(7):867.

24. Craven DE, Steger KA: Epidemiology of nosocomial pneumonia. New perspectives on an old disease. Chest 1995, 108(2 Suppl): IS.

25. Rello J, Sonora R, Jubert P, Artigas A, Rue M, Valles J: Pneumonia in intubated patients: role of respiratory airway care. Am J Respir Crit Care Med 1996, I54(I): I II.

26. De Kievit TR, Gillis R, Marx S, Brown C, Iglewski BH: Quorumsensing genes in Pseudomonas aeruginosa biofilms: their role and expression patterns. Appl Environ Microbiol 200I, 67(4): 1865.

27. Sauer K, Camper AK, Ehrlich GD, Costerton JW, Davies DG: Pseudomonas aeruginosa displays multiple phenotypes during development as a biofilm. J Bacteriol 2002, I 84(4): | | 40.

28. Davey ME, Caiazza NC, O'Toole GA: Rhamnolipid surfactant production affects biofilm architecture in Pseudomonas aeruginosa PAOI. J Bacteriol 2003, I 85(3): 1027.

29. Drenkard E, Ausubel FM: Pseudomonas biofilm formation and antibiotic resistance are linked to phenotypic variation. Nature 2002, 4 I 6(6882):740.

30. Tateda K, Comte R, Pechère JC, Köhler T, Yamaguchi K, Van Delden $C$ : Azithromycin inhibits quorum sensing in Pseudomonas aeruginosa. Antimicrob Agents Chemother 2001, 45(6): I930-1933.

31. Gillis RJ, Iglewski BH: Azithromycin retards Pseudomonas aeruginosa biofilm formation. J Clin Microbiol 2004, 42(I 2):5842.

32. West SE, Kaye SA, Hamood AN, Iglewski BH: Characterization of Pseudomonas aeruginosa mutants that are deficient in exotoxin $A$ synthesis and are altered in expression of regA, a positive regulator of exotoxin A. Infect Immun 1994, 62(3):897.

33. Terry JM, Pina SE, Mattingly SJ: Role of energy metabolism in conversion of nonmucoid Pseudomonas aeruginosa to the mucoid phenotype. Infect Immun 1992, 60(4): I 329

34. Mahul P, Auboyer C, Jospe R, Ros A, Guerin C, el Khouri Z, Galliez $M$, Dumont A, Gaudin O: Prevention of nosocomial pneumonia in intubated patients: respective role of mechanical subglottic secretions drainage and stress ulcer prophylaxis. Intensive Care Med 1992, I8(I):20.

35. Inglis TJ, Millar MR, Jones JG, Robinson DA: Tracheal tube biofilm as a source of bacterial colonization of the lung. J Clin Microbiol 1989, 27(9):20|4

36. Inglis TJ, Lim TM, Ng ML, Tang EK, Hui KP: Structural features of tracheal tube biofilm formed during prolonged mechanical ventilation. Chest 1995, I 08(4): 1049

37. Valles J, Artigas A, Rello J, Bonsoms N, Fontanals D, Blanch L, Fernandez R, Baigorri F, Mestre J: Continuous aspiration of subglottic secretions in preventing ventilator- associated pneumonia. Ann Intern Med 1995, I 22(3): I79.

38. Pearson JP, Pesci EC, Iglewski BH: Role of Pseudomonas aeruginosa las and rhl quorum-sensing systems in the control of elastase and rhamnolipid biosynthesis genes. J Bacteriol 1997, I 79( I 8):5756.

39. Van Delden C, Comte R, Bally M: Stringent response activates quorum sensing and modulates cell density-dependent gene expression in Pseudomonas aeruginosa. I Bacteriol 200I, I 83( I 8):5376.

40. Mahenthiralingam E, Campbell ME, Foster J, Lam JS, Speert DP: Random amplified polymorphic DNA typing of Pseudomonas aeruginosa isolates recovered from patients with cystic fibrosis. I Clin Microbiol 1996, 34(5): I I 29.

4I. Van Delden C, Pesci EC, Pearson JP, Iglewski BH: Starvation selection restores elastase and rhamnolipid production in a $\mathbf{P s e u}$ domonas aeruginosa quorum-sensing mutant. Infect Immun 1998, 66(9):4499.

42. Köhler T, Van Delden C, Curty LK, Hamzehpour MM, Pechère JC: Overexpression of the MexEF-OprN multidrug efflux system affects cell-to-cell signaling in Pseudomonas aeruginosa. Bacteriol 2001, I 83( I 8):52 I3-5222.

43. O'Toole GA, Kolter R: Flagellar and twitching motility are necessary for Pseudomonas aeruginosa biofilm development. Mol Microbiol 1998, 30(2):295.
Publish with Bio Med Central and every scientist can read your work free of charge

"BioMed Central will be the most significant development for disseminating the results of biomedical research in our lifetime. "

Sir Paul Nurse, Cancer Research UK

Your research papers will be:

- available free of charge to the entire biomedical community

- peer reviewed and published immediately upon acceptance

- cited in PubMed and archived on PubMed Central

- yours - you keep the copyright
BioMedcentral 